Slavica

bruxellensia

\section{Slavica bruxellensia}

Revue polyphonique de littérature, culture et histoire

slaves

$4 \mid 2009$

Espaces slaves / espaces belges

\title{
Poétique du film. Textes des formalistes russes sur le cinéma.
}

\section{Galina Subbotina}

\section{OpenEdition}

Journals

Édition électronique

URL : http://journals.openedition.org/slavica/290

DOI : $10.4000 /$ slavica. 290

ISSN : 2034-6395

Éditeur

Université libre de Bruxelles - ULB

Édition imprimée

Pagination : 69-70

ISSN : 2031-7654

Référence électronique

Galina Subbotina, "Poétique du film. Textes des formalistes russes sur le cinéma. », Slavica bruxellensia [En ligne], 4 | 2009, mis en ligne le 15 octobre 2009, consulté le 22 septembre 2020. URL : http:// journals.openedition.org/slavica/290 ; DOI : https://doi.org/10.4000/slavica.290

Ce document a été généré automatiquement le 22 septembre 2020.

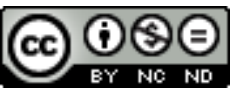

Les contenus de Slavica bruxellensia sont mis à disposition selon les termes de la Licence Creative Commons Attribution - Pas d'Utilisation Commerciale - Pas de Modification 3.0 France. 


\title{
Poétique du film. Textes des formalistes russes sur le cinéma.
}

\author{
Galina Subbotina
}

\section{RÉFÉRENCE}

Chklovski V., Eikhenbaum B., Kazanski B., Mikhaïlov E., Moskvine A., Piotrovski A., Tynianov I., Poétique du film. Textes des formalistes russes sur le cinéma., Lausanne, L'Âge d'homme, 2008, 264 p. Traduit du russe par Valérie Posener, Régis Gayraud et JeanChristophe Peuch. 
Dans le domaine littéraire, l'apport des formalistes russes de Moscou et de Petrograd (1915-1930) est unanimement reconnu. On sait moins qu'ils se sont très tôt intéressés au cinéma. La présente édition s'organise autour de Poétique du film, l'ouvrage collectif des formalistes publié en 1927 à Leningrad. Ce texte, devenu un classique de la théorie du cinéma dans plusieurs pays, demeurait inédit en français. La traduction en est signée Valérie Posener, Régis Gayraud et Jean-Christophe Peuch. L'ouvrage comporte une introduction, des notices sur les auteurs, un glossaire - bien élaboré - et une bibliographie internationale, réalisés par François Albéra, professeur d'histoire et d'esthétique du cinéma à l'Université de Lausanne (Suisse) et auteur de plusieurs ouvrages importants sur le cinéma russe.

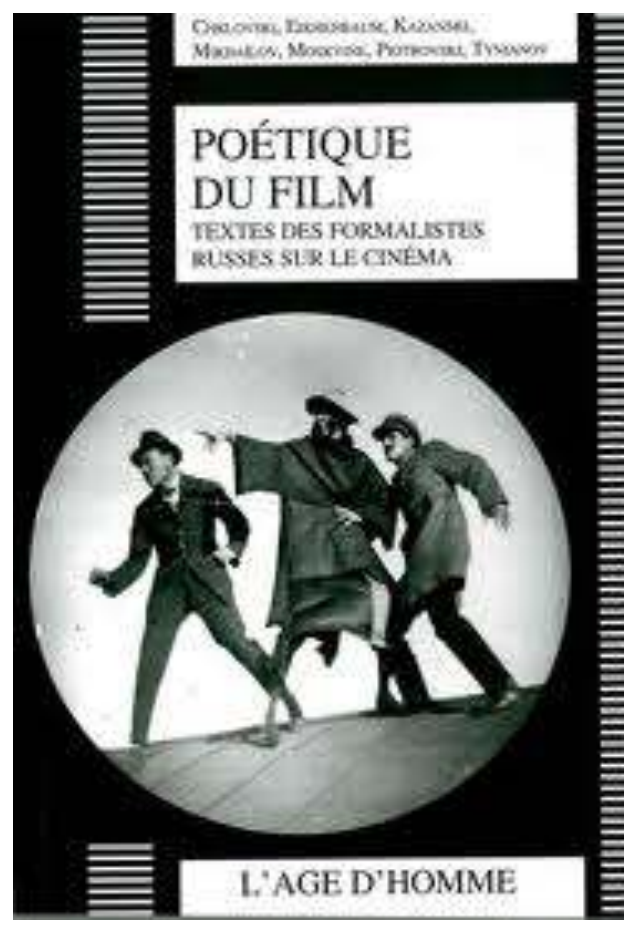

Bien que les problèmes du cinéma soient au centre de cette publication, elle est susceptible d'intéresser non seulement les historiens de cet art mais également les philologues.

3 La raison première de ce double intérêt est liée à ce que les formalistes mettent en parallèle le cinéma, art encore tout jeune au début du XX $\mathrm{XX}^{\mathrm{e}}$ siècle, avec la littérature, la peinture, la photographie et la musique. Ainsi, ce recueil préfigure à certains égards un nouveau type d'analyse comparatiste: le rapprochement non seulement de textes littéraires de différents pays, mais aussi d'œuvres relevant de différents arts.

4 En outre, nous constatons, à travers ce livre, que pour leur analyse du cinéma les formalistes russes utilisent le même cadre théorique que pour leurs travaux sur la littérature. Ils se penchent par exemple sur le problème du rôle de l'expérimentation dans la création d'une œuvre cinématographique et dans le développement de l'art en général, question qui est très caractéristique de leurs études littéraires. La naissance du cinéma est décrite dans des termes utilisés par ailleurs pour retracer l'apparition d'un nouveau genre, comme le passage de la périphérie du système des arts vers le centre de ce système. Le film est analysé sur la base d'un parallèle avec le langage, compris comme une unité de plusieurs "phrases» dont chacune se compose d'éléments plus petits.

5 Ce recueil pose aussi les prémices de l'approche sémiologique qui se développera dans les années 1960. Les formalistes examinent le problème de la compréhension du film par le public. Ils soulignent l'existence d'un discours caché, qui est exprimée par les images dans une forme non verbale.

6 Dans le domaine proprement cinématographique, ce sont les études de Boris Ejhenbaum et de Jurij Tynjanov qui ont le plus de portée. Ejhenbaum cherche à établir les procédés techniques qui permettent au cinéma d'exprimer toute sa richesse 
sémantique. Ces procédés ne sont pas très nombreux, ils se résument, pour l'essentiel, aux plans et aux mouvements de caméra. C'est grâce au montage que le réalisateur, selon Ejhenbaum, peut résoudre les tâches stylistiques les plus complexes en utilisant successivement des plans contrastés, métaphoriques, symboliques, etc. Jurij Tynjanov quant à lui expose sa théorie des deux types du cinéma : prosaïque (orienté vers la représentation des chaînes événementielles) et poétique (orienté vers la représentation d'un contenu émotionnel, philosophique, psychologique).

7 En somme, voici un ouvrage important où les voix des formalistes les plus connus se mêlent à celles de ceux qu'un public plus large doit encore découvrir. Soulignons encore l'importance du défi auquel firent face les traducteurs, qui parvinrent avec brio à rendre en français une langue si précise et si pointue.

\section{INDEX}

Index géographique : Russie, URSS

Mots-clés : cinéma russe, cinéma soviétique, formalisme russe

Index chronologique : communisme, entre-deux-guerres

\section{AUTEURS}

\section{GALINA SUBBOTINA}

Doctorante, membre du Centre de recheche ALITHILA et lectrice de russe à l'Université Charlesde-Gaulle Lille3 (Villeneuve d'Ascq, France) 